\title{
Integrative Analysis of 334 Patients with Blister-Like Aneurysms
}

W e read with great interest a recent article by Peschillo et $\mathrm{al}^{1}$ on blister-like aneurysms. The authors performed a meta-analysis of 334 patients with blister-like aneurysms who were treated with either an operation or endovascular therapy. The authors found that endovascular treatment had lower morbidity and mortality and provided a better outcome compared with surgical approaches, especially in patients with low Hunt and Hess $(\mathrm{HH})$ scale and Fisher grades. Only the $\mathrm{HH}$ and Fisher grades were clear predictors of outcomes in multivariate analysis, but the method of treatment was not.

We commend the authors for performing a meta-analysis of this type of aneurysm because it is a rare disease with imprecise definition and no existing guidelines on optimal management. ${ }^{2}$ However, we have significant concerns about the methodologies and results. First, the authors did not specify how they handled the data in their meta-analysis. It seems that the authors performed an integrative analysis of individual patients pooled from each individual study instead of a "meta-analysis." If this is the case, did the authors exclude a study because it did not specify clinical presentation, method of treatment, or outcome? The exact criteria used for study inclusion were not clear; this problem increases the potential for publication bias. A previous systematic review of 331 patients showed that results from multivariate analysis were influenced by the number of cases in a single study and the journal Impact Factor. ${ }^{3}$

Second, for studies that did not provide information on $\mathrm{HH}$ or Fisher grade, did the authors assign their own scores as they did for the modified Rankin Scale score? From our experience, assignment of these parameters on the basis of limited information reported in published articles can significantly bias the results. In addition, inclusion of both $\mathrm{HH}$ and Fisher grades simultaneously in the multivariate analysis may be inappropriate because they can provide similar information (ie, covariates).

Third, the authors did not specify whether all the patients included in the analysis presented with subarachnoid hemorrhage. For example, of the 8 patients with blister-like aneurysms presented by Chalouhi et al, ${ }^{4} 1$ patient presented with sentinel headache, and in 2 patients, the aneurysm was incidentally discovered. If a patient presents with $\mathrm{SAH}$, the treatment considerations will be completely different from those for a patient whose blister-like aneurysm was discovered incidentally. ${ }^{5}$ Similarly, the outcomes will be significantly different as well.

Last, publications from earlier years are likely to be on micro- surgical management or coils, while more recent studies will focus on new endovascular treatment methods. Consequently, a patient who would be selected for endovascular treatment today on the basis of presentation would have undergone microsurgical clipping in 1997. This trend is clearly shown in Fig 4 of Szmuda et al. ${ }^{3}$

In summary, the authors presented interesting results based on an integrative analysis of patients with blister-like aneurysms. Even though one acknowledges the inherent limitations of such analysis, the study can still benefit from better definitions of the following: 1) inclusion criteria, 2) handling of missing data (eg, $\mathrm{HH}$ and Fisher grades, $\mathrm{mRS}$ ), and 3) presentation of patients (SAH versus incidental).

Li Yang was supported by National Natural Science Foundation, 2014, grant number 81301988 and the Shenghua Yuyin Experts Project of Central South University.

\section{REFERENCES}

1. Peschillo S, Cannizzaro D, Caporlingua A, et al. A systematic review and meta-analysis of treatment and outcome of blister-like aneurysms. AJNR Am J Neuroradiol 2015 Dec 3. [Epub ahead of print] CrossRef Medline

2. Gonzalez AM, Narata AP, Yilmaz $\mathrm{H}$, et al. Blood blister-like aneurysms: single center experience and systematic literature review. Eur J Radiol 2014;83:197-205 CrossRef Medline

3. Szmuda T, Sloniewski P, Waszak PM, et al. Towards a new treatment paradigm for ruptured blood blister-like aneurysms of the internal carotid artery? A rapid systematic review. J Neurointerv Surg 2015 Mar 19. [Epub ahead of print] CrossRef Medline

4. Chalouhi N, Zanaty M, Tjoumakaris S, et al. Treatment of blisterlike aneurysms with the Pipeline embolization device. Neurosurgery 2014;74:527-32; discussion 532 CrossRef Medline

5. van Rooij WJ, de Gast A, Sluzewski M, et al. Coiling of truly incidental intracranial aneurysms. AJNR Am J Neuroradiol 2006;27:293-96 Medline

$$
\begin{array}{r}
\text { L. Yang } \\
\text { X. Huang } \\
\text { Th. Tan } \\
\text { Department of Neurology } \\
\text { Changsha, China } \\
\text { H. Zhou } \\
\text { Department of Neurology } \\
\text { Che First Xiangya Hospital of Central South University } \\
\text { Changhat China } \\
\text { H.X. Bai } \\
\text { Department of Radiology }
\end{array}
$$

